\title{
Environments For Healthy Living (EFHL) Griffith birth cohort study: characteristics of sample and profile of antenatal exposures
}

Cate M Cameron ${ }^{1,2}$, Paul A Scuffham 1,2, Rania Shibl 1,2, ShuKay Ng ${ }^{1,2}$, Rani Scott ${ }^{1}$, Anneliese Spinks ${ }^{3,2}$, Gabor Mihala ${ }^{1}$, Andrew Wilson ${ }^{4}$, Elizabeth Kendall ${ }^{5,2}$, Neil Sipe $^{6,2}$ and Roderick J McClure ${ }^{7 *}$

\begin{abstract}
Background: The Environments for Healthy Living (EFHL) study is a repeated sample, longitudinal birth cohort in South East Queensland, Australia. We describe the sample characteristics and profile of maternal, household, and antenatal exposures. Variation and data stability over recruitment years were examined.

Methods: Four months each year from 2006, pregnant women were recruited to EFHL at routine antenatal visits on or after 24 weeks gestation, from three public maternity hospitals. Participating mothers completed a baseline questionnaire on individual, familial, social and community exposure factors. Perinatal data were extracted from hospital birth records. Descriptive statistics and measures of association were calculated comparing the EFHL birth sample with regional and national reference populations. Data stability of antenatal exposure factors was assessed across five recruitment years (2006-2010 inclusive) using the Gamma statistic for ordinal data and chi-squared for nominal data.
\end{abstract}

Results: Across five recruitment years 2,879 pregnant women were recruited which resulted in 2904 live births with 29 sets of twins. EFHL has a lower representation of early gestational babies, fewer still births and a lower percentage of low birth weight babies, when compared to regional data. The majority of women (65\%) took a multivitamin supplement during pregnancy, 47\% consumed alcohol, and 26\% reported having smoked cigarettes. There were no differences in rates of a range of antenatal exposures across five years of recruitment, with the exception of increasing maternal pre-pregnancy weight ( $p=0.0349)$, decreasing rates of high maternal distress ( $p=0.0191)$ and decreasing alcohol consumption $(p<0.0001)$.

Conclusions: The study sample is broadly representative of births in the region and almost all factors showed data stability over time. This study, with repeated sampling of birth cohorts over multiple years, has the potential to make important contributions to population health through evaluating longitudinal follow-up and within cohort temporal effects.

Trial registration: Australian and New Zealand Clinical Trials Registry ACTRN12610000931077

Keywords: Birth cohort, Longitudinal study, Epidemiology, Demographics, Descriptive analysis

\footnotetext{
* Correspondence: rod.mcclure@monash.edu

${ }^{7}$ Injury Research Institute, Monash University, Melbourne, Victoria 3800,

Australia

Full list of author information is available at the end of the article
} 


\section{Background}

Health is the product of a complex interaction of factors relating to societal norms, a person's local physical and social environment, and their biological and psychological capacities [1-3]. While public health researchers and practitioners recognise the importance of a multilevel, ecological model of disease causation and health promotion, [4,5] there has been limited research successfully quantifying these relationships in way that can support population based interventions [6]. The primary reason for this is that most previous aetiological and implementation research designs are not consistent with the multi-level logic that underpins our understanding of disease causation.

In order to advance the ecological understanding of disease causation, epidemiological research needs to be able to quantify the contextual factors as well as the proximal risk factors responsible for relevant health outcomes. There is a growing interest throughout the world in developing study designs that enable this level of multi-level analyses [7].

Environments for Healthy Living (EFHL) is a birth cohort study being conducted in South East Queensland, Australia, designed specifically to operationalise the ecological model of disease causation [5] and thus provide information required to develop policy driven improvements in population health. Using methods previously described, [8] data collected in this study include biological samples, participant surveys, medical record and administrative data linkage, land use and spatial variables. With a planned total cohort of nearly 4000 mother/ infant dyads being recruited from a circumscribed study region, comprising communities across a broad range of socioeconomic exposures, this study has the capacity to address questions of contemporary importance.

The aim of this paper is to provide a comprehensive baseline profile for the first five recruitment years of the EFHL birth cohort and determine the ability to analyse the repeated cohort samples separately or combined. The study sample characteristics and maternal, household and, community exposures are described. Variation and data stability over recruitment years is examined.

\section{Methods}

\section{Study design}

EFHL is a repeated sample, longitudinal birth cohort in South East Queensland and Tweed in Northern New South Wales (NSW) Australia. The study has been registered with the Australian New Zealand Clinical Trials Registry (ACTRN12610000931077).

\section{Study population and participants}

The study population includes all births from three geographically defined contiguous Health Districts (Logan,
Beaudesert and the Gold Coast in Queensland; and Northern Rivers/Tweed in NSW) from 2006-2012. These districts cover an area of almost 6,000 square kilometres, encompassing approximately 30\% of Queensland's population [9]. Eligible participants were recruited from the three public maternity hospitals in the participating districts (Logan, Gold Coast and The Tweed Hospitals). Women attending private maternity hospitals, birthing centres and planned home births in the study region were not included. Women waiting for antenatal clinic appointments, on or after their routine 24 week antenatal visit, were approached by research trained midwives, provided with a detailed explanation of the study aims, and invited to participate. Pregnant women aged less than 16 years or unable to provide informed consent were excluded. The study sample is the offspring of women enrolled in EFHL.

\section{Recruitment}

Women were recruited to participate in the EFHL study during four months of each year since 2006. As a consequence of unavoidable logistics involved with recruiting from multiple hospital sites, there was a small variation in the month recruitment began across the years. The pilot year commenced in November 2006; open recruitment from August in 2007 and 2008; and from 2009 onwards the four month recruitment period began in July. The EFHL cohort methodology has been described in full elsewhere [8]. Baseline data is currently available for five of the observational cohorts enrolled (2006-2010 inclusive).

\section{Data sources, instruments and scales}

Baseline data was obtained from two key data sources namely a participant maternal baseline survey and hospital perinatal data related to the birth of the child. The maternal baseline questionnaire was self-administered, and consisted of 48 multi-item questions taking approximately 30 minutes to complete. Items included maternal, family and household characteristics, socio-economic factors, Kessler 6 (K6) psychological distress scale, [10,11] short form of the Family Environment Scale (FES), [12,13] neighbourhood and community connectedness (NCC), [14] maternal smoking and drinking behaviour, health supplement usage, and recreational substances used during pregnancy. Perinatal data was extracted from the medical records following maternal discharge from hospital. Data items included previous pregnancies, maternal conditions, obstetric care and complications, delivery information, and baby information such as gender, plurality, gestational age, birth weight and any complications. Information collected on the biological father has been specified as 'paternal' whereas information collected on the current partner (which was not necessarily the biological father) has been specified as 'partner' information. 
Variable calculation and classifications include: Using Australian National birth weights for full-term singletons, birth weight was classified as low $(<2500 \mathrm{~g})$, normal (2500-4000 g) and high (>4000 g) [15]. BMI was calculated from weight in kilograms and height in meters (Weight/Height ${ }^{2}$ ). Pre-pregnancy maternal BMI measures were determined by self-report and paternal BMI measures by proxy-report from the maternal participant. BMI was classified as underweight $(<18.5)$, normal weight (18.5-24.9), overweight (25.0-29.9) and obese (>30) [16]. Maternal and paternal ages were calculated in years at the time of the birth of their child.

Women and their partners were classified as employed if they reported working full-time, part-time, were selfemployed or on paid maternity/paternity leave at the time of enrolment. Gross annual household income was reported in $\$ 10,000$ increments and standardised in AUD \$2010 values using published Consumer Price Index $[17,18]$. Standardised median household income is reported along with the income share in each quintile as an indicator of income distribution for the five recruitment years.

The $\mathrm{K} 6$ is intended to yield a global measure of "psychological distress" based on questions about the level of anxiety and depressive symptoms in the most recent 4week period. The $\mathrm{K} 6$ has been widely used and has demonstrated excellent internal consistency, reliability and the ability to discriminate between community mental health cases and non-cases [10,19]. The six-items form a 24-point scale and the following cut-offs were used: No or low distress (0-7), moderate distress (8-12), and high distress (13-24) [11,20].

The NCC is a five item measure of perception of satisfaction with the local community [14]. NCC scores were classified as good (5-8), average (9-14) and poor (1525 ) based on \pm 1 SD mean. Data was not available from the 2006 pilot cohort for the K6 and NCC.

For the purpose of this paper, self-reported alcohol consumption, recreational drug use, and multivitamin supplement use during pregnancy were dichotomised. Alcohol consumption was defined as any consumption of alcohol during pregnancy regardless of period, frequency, or quantity. Drug use for recreational or non-medical purposes, was asked using questions modified for pregnancy from the Australian National Drug Strategy Household Survey 2004 [21]. This included a range of drugs including steroids, barbiturates, cannabis, heroin, methamphetamines/amphetamines, cocaine, ecstasy, ketamine, solvents, and kava. A 'prefer not to answer' option was also provided. Multivitamin supplement use included any general multivitamin or pregnancy specific supplement taken during pregnancy.

\section{Analysis}

Data cleaning and scoring was undertaken using SAS 9.2 software. Aggregate results were compared to regional and national reference population data from the Queensland and NSW Perinatal Data Collection systems, [22,23]. Australian Institute of Health and Welfare [24-27] and Australian Bureau of Statistics [28]. Changes in maternal, paternal, and household antenatal exposures were examined across each recruitment year to assess data stability. Measures of association and tests for trends were performed using Pearson's chi-squared for nominal data and Gamma statistic for collapsed ordinal data. Differences in household incomes between the five years were tested with the Median-test [29]. Analyses were undertaken using SAS 9.2 and Stata 12. A significance level of 5\% was used.

\section{Ethical approval}

The protocol for the EFHL study was approved by the Griffith University Human Research Ethics Committee (MED/16/06/HREC, MED/23/11/HREC). Additional ethical approval for participant recruitment was also obtained from each of the three participating public maternity hospitals (Logan Hospital HREC/06/QPAH/96, Gold Coast Hospital HREC/06/GCH/52, The Tweed Hospital NCAHS HREC $358 \mathrm{~N}$ ). The protocol for the EFHL study conforms to the provisions of the Declaration of Helsinki in 1995 (as revised in Tokyo 2004). Each participant gave written informed consent for the release of hospital perinatal data related to the birth of their child, completion of a participant maternal baseline survey, and for individual followup. All research data are de-identified and stored for analysis.

\section{Results}

\section{EFHL recruitment}

Figure 1 presents a flow diagram of the recruitment process, including all births in the Australian reference population and the study population (Logan, Beaudesert, Gold Coast and Northern Rivers Health Districts) from 2006 to 2010 inclusive [22,23]. An estimated 12,430 births occurred at the three recruitment hospitals during the annual four month recruitment periods between 2006 and 2010.

Of the total number of women approached $(n=6,251)$, almost half (46\%) were enrolled in the EFHL birth cohort study, with an average of 576 women enrolled each fourmonth recruitment period. A small number of women were not enrolled due to incomplete or missing questionnaires/consents which were unable to be resolved $(n=50)$. The remaining either formally declined to participate when approached $(n=654)$ or failed to return the enrolment packages $(n=2,668)$. From 2006 to 2010 inclusive (five observational cohorts) 2,879 pregnant women were recruited, which resulted in 2904 live births with 29 sets of twins. EFHL participants accounted for approximately $6.4 \%$ of all births in the study population from the three 


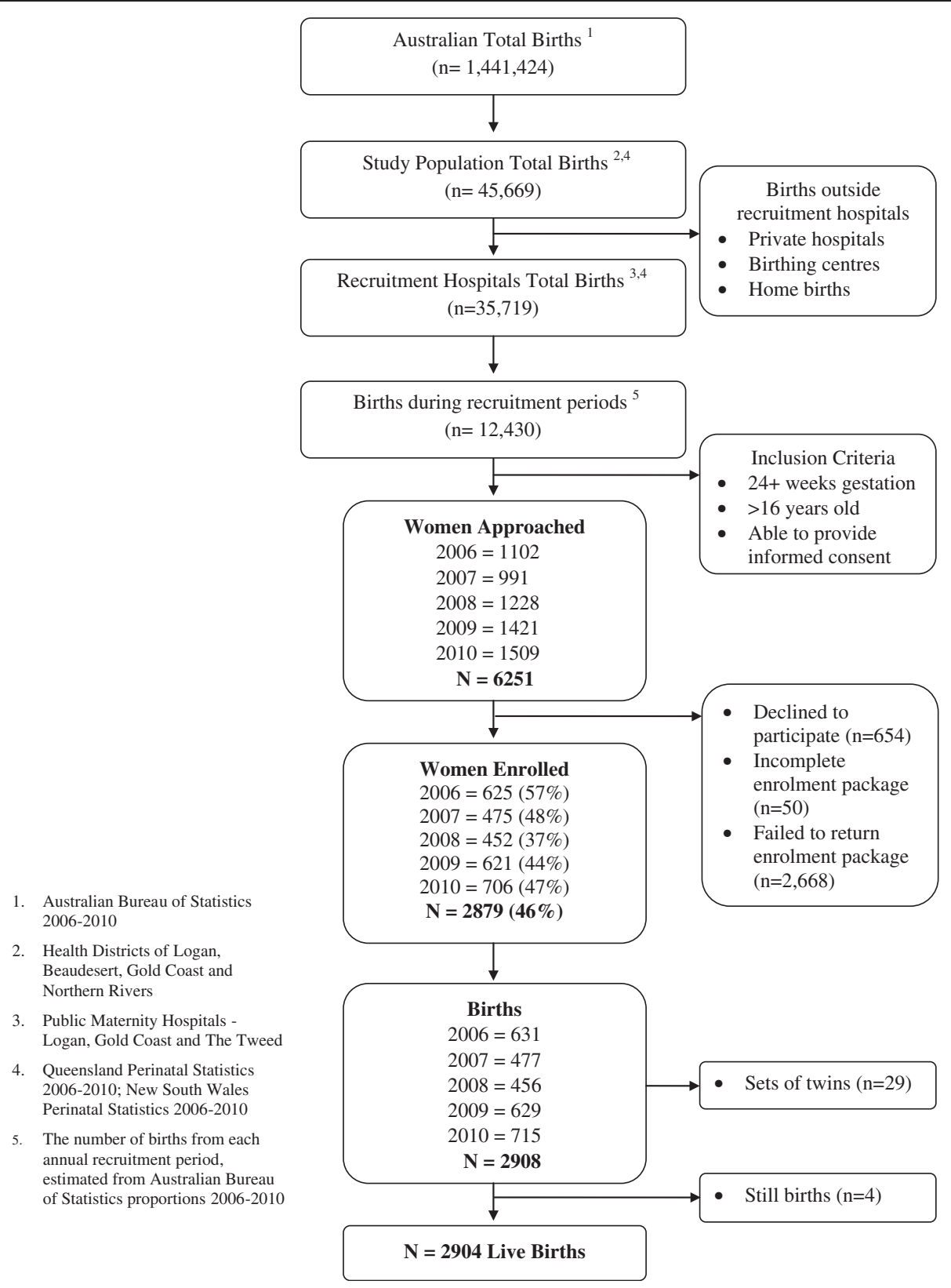

Figure 1 Flow diagram of eligibility and recruitment for the EFHL cohorts 2006-2010.

Health Districts for the full five years (January 2006 December 2010). The EFHL study sample represents $23.4 \%$ of the total births in the target population hospitals during the annual recruitment periods.

\section{EFHL infant sample characteristics}

Table 1 presents the sample characteristics of the 20062010 EFHL birth cohorts with comparative regional study and national reference population data. There were some differences in the birth characteristics of the EFHL sample when compared to population data. EFHL has a lower representation of early gestational babies with $3.3 \%$ of
EFHL babies born less than 37 weeks gestation, versus $7.0 \%$ regionally and $8.2 \%$ nationally $(\mathrm{p}<0.001)$. The study sample has fewer still births, and a lower proportion of babies weighing less than $2500 \mathrm{~g}$. There were no differences in the gender distribution or the plurality of births from expected study population rates.

\section{Profile of maternal, household and demographic antenatal exposures}

The maternal age of women in the EFHL study ranged from 16 years to 48 years, with a median age of 29 years. The EFHL cohort was younger when compared with all 
Table 1 Sample characteristics of the EFHL infant cohorts 2006-2010, compared with regional and national population data

\begin{tabular}{|c|c|c|c|c|}
\hline & EFHL study sample & Study population ${ }^{a}$ & Reference population ${ }^{\mathbf{b}}$ & P-value \\
\hline Infant Characteristics & $\mathrm{N}=2908$ & $\mathrm{~N}=45,669$ & $N=1,441,424$ & \\
\hline \multicolumn{5}{|l|}{ Gender of infant } \\
\hline Males & $1448(50.5)$ & $23,498(51.5)$ & $735,479(51.4)$ & 0.315 (Study) \\
\hline Females & $1420(49.5)$ & $22,170(48.5)$ & $694,495(48.6)$ & 0.312 (Reference) \\
\hline Missing & 40 & 1 & 11,450 & \\
\hline \multicolumn{5}{|l|}{ Plurality } \\
\hline Singleton & $2850(98.0)$ & $44,568(97.6)$ & $1,395,372(96.8)$ & 0.173 (Study) \\
\hline Multiple & $58(2.0)$ & $1,101(2.4)$ & $46,052(3.2)$ & $<0.001$ (Reference) \\
\hline Missing & 0 & 0 & 0 & \\
\hline \multicolumn{5}{|l|}{ Gestational age at birth } \\
\hline$<28$ weeks & $0(0.0)$ & $273(0.6)$ & $12,881(0.9)$ & $<0.001$ (Study) \\
\hline 28-36 weeks & $95(3.3)$ & $2,912(6.4)$ & $105,235(7.3)$ & $<0.001$ (Reference) \\
\hline 37-41 weeks & $2734(96.1)$ & $42,227(92.5)$ & $1,308,933(90.8)$ & \\
\hline$>41$ weeks & $17(0.6)$ & $245(0.5)$ & $13,761(1.0)$ & \\
\hline Missing & 62 & 12 & 614 & \\
\hline \multicolumn{5}{|l|}{ Live births } \\
\hline Live & 2904 (99.9) & $45,368(99.3)$ & $1,430,500(99.2)$ & 0.001 (Study) \\
\hline Still born & $4(0.1)$ & $301(0.7)$ & $10,815(0.8)$ & $<0.001$ (Reference) \\
\hline Missing & 0 & 0 & 109 & \\
\hline \multicolumn{5}{|l|}{ Birth weight } \\
\hline$<2500 \mathrm{~g}$ & $76(2.7)$ & $2,484(5.4)$ & $97,524(6.8)$ & $<0.001$ (Study) \\
\hline $2500-3999 \mathrm{~g}$ & 2319 (81.6) & $37,287(81.7)$ & $1,170,968(81.3)$ & $<0.001$ (Reference) \\
\hline$>4000$ & $448(15.7)$ & $5,894(12.9)$ & $172,169(11.9)$ & \\
\hline Missing & 65 & 4 & 763 & \\
\hline
\end{tabular}

a Study population includes all births in the Logan, Beaudesert, Gold Coast and Northern Rivers Health Districts. Data sources: Queensland Perinatal Statistics 2006-2010; New South Wales Perinatal Statistics 2006-2010.

${ }^{\mathrm{b}}$ Reference Population includes all births in Australia 2006-2010. Data sources: National Perinatal Statistics 2006-2010.

c Pearsons chi-squared.

women giving birth in the study region, with more women aged $20-24$ years $(\mathrm{p}=0.001)$ [24-27]. The paternal age ranged from 15 years to 70 years, with a median age of 31 years. The proportion of high risk pregnancy complications, including gestational diabetes (5.3\%) and essential hypertension $(<1 \%)$ were consistent with Queensland rates [24-27].

Table 2 presents the antenatal exposure data collected for each of the five cohort years (2006-2010). The study sample has a higher proportion of mothers born outside of Australia compared with national maternal population data (28.8\% versus 25.4\%) [24-27]. Over $35 \%$ of the mothers in the study were either overweight or obese with pre-pregnancy BMIs $>25$. Of note, less than half of all mothers had a pre-pregnancy BMI in the normal weight range. More than half of the fathers were reported to be either overweight or obese (53.0\%). Of the women enrolled, almost $21 \%$ did not complete high school education and almost half were either unemployed or not in the labour force at the time of enrolment. This included those who were on disability pensions and homemakers. Similarly, $22.7 \%$ of partners did not complete high school education and $7.5 \%$ were unemployed or not in the labour force at the time of enrolment. The majority of families were reported as having two parents in the household and $38.9 \%$ reported having no other children living in the house at the time of baseline enrolment (Table 2).

At the time of enrolment the median total gross household income was $\$ 62,946$ in AUD\$2010 values; the lowest income quintile contributed $7.0 \%$ to the total wealth of the cohort whereas the highest income quintile contributed 40.0\%. The EFHL cohort demonstrated lower household incomes when compared with Queensland household incomes for 2006-2010 [17]. In Queensland, the lowest income quintile contributed $4.2 \%$ and the highest income quintile contributed $45.7 \%$ to the total wealth.

While the majority of families reported satisfaction with the area in which they lived (86.6\%), only $15.2 \%$ 
Table 2 Profile of maternal, family and household antenatal exposures for the EFHL cohorts 2006-2010

\begin{tabular}{|c|c|c|c|c|c|c|c|}
\hline & $\begin{array}{c}2006 \\
(n=625)\end{array}$ & $\begin{array}{c}2007 \\
(n=475)\end{array}$ & $\begin{array}{c}2008 \\
(n=452)\end{array}$ & $\begin{array}{c}2009 \\
(n=621)\end{array}$ & $\begin{array}{c}2010 \\
(n=706)\end{array}$ & $\begin{array}{l}\text { All Years } \\
(n=2879)\end{array}$ & $P$ value \\
\hline Maternal Characteristics & n (\%) & n (\%) & n (\%) & n (\%) & n (\%) & n (\%) & \\
\hline \multicolumn{8}{|l|}{ Maternal age } \\
\hline$<25$ years & 147 (23.6) & $118(24.9)$ & $112(24.8)$ & $142(22.9)$ & $184(26.1)$ & $703(24.5)$ & \multirow[t]{5}{*}{$0.5367^{\mathrm{a}}$} \\
\hline $25-29$ years & $172(27.5)$ & $126(26.5)$ & $123(27.3)$ & $199(32.2)$ & $195(27.7)$ & $815(28.4)$ & \\
\hline 30-34 years & $187(30.0)$ & $133(28.0)$ & $119(26.4)$ & $142(22.9)$ & $180(25.6)$ & $761(26.5)$ & \\
\hline 35-39 years & $100(16.0)$ & $76(16.0)$ & $77(17.1)$ & $105(17.0)$ & $114(16.2)$ & $472(16.4)$ & \\
\hline $40+$ years & $18(2.9)$ & $22(4.6)$ & $20(4.4)$ & $31(5.0)$ & $31(4.4)$ & $122(4.2)$ & \\
\hline \multicolumn{8}{|l|}{ Missing $=6$} \\
\hline \multicolumn{8}{|l|}{ Maternal BMI } \\
\hline Underweight (<18.5) & $104(16.8)$ & $80(17.1)$ & 77 (17.2) & $109(17.7)$ & $120(17.2)$ & $490(17.2)$ & \multirow[t]{4}{*}{$0.0349^{\mathrm{a}}$} \\
\hline Normal weight (18.5-24.9) & $320(51.8)$ & $225(48.1)$ & $222(49.5)$ & $278(45.3)$ & $311(44.6)$ & $1356(47.7)$ & \\
\hline Overweight (25.0-29.9) & $111(18.0)$ & 89 (19.0) & 89 (19.9) & $119(19.4)$ & $137(19.7)$ & $545(19.1)$ & \\
\hline Obese $(>30)$ & $83(13.4)$ & $74(15.8)$ & $60(13.4)$ & $108(17.6)$ & $129(18.5)$ & $454(16.0)$ & \\
\hline \multicolumn{8}{|l|}{ Missing $=34$} \\
\hline \multicolumn{8}{|l|}{ Country of Birth } \\
\hline Australia & 460 (73.6) & $348(73.3)$ & $313(69.4)$ & $434(69.9)$ & $493(69.9)$ & $2048(71.2)$ & \multirow[t]{2}{*}{$0.3392^{b}$} \\
\hline Other & $165(26.4)$ & $127(26.7)$ & $138(30.6)$ & $187(30.1)$ & $212(30.1)$ & $829(28.8)$ & \\
\hline \multicolumn{8}{|l|}{ Missing $=2$} \\
\hline \multicolumn{8}{|l|}{ Highest level of education } \\
\hline Not complete school & $129(20.7)$ & $93(19.7)$ & 88 (19.6) & $147(23.8)$ & $143(20.4)$ & $600(20.9)$ & \multirow[t]{4}{*}{$0.4967^{\mathrm{a}}$} \\
\hline Completed high school & $201(32.3)$ & $163(34.5)$ & 139 (30.9) & $178(28.8)$ & $212(30.2)$ & 893 (31.2) & \\
\hline Trade/Apprenticeship & $179(28.7)$ & $131(27.7)$ & $135(30.0)$ & $186(30.1)$ & $198(28.3)$ & $829(28.9)$ & \\
\hline University degree & $114(18.3)$ & $86(18.2)$ & 88 (19.6) & $107(17.3)$ & $148(21.1)$ & $543(19.0)$ & \\
\hline \multicolumn{8}{|l|}{ Missing $=14$} \\
\hline \multicolumn{8}{|l|}{ Employment Status } \\
\hline Employed & $314(50.4)$ & $241(51.2)$ & $223(49.8)$ & $310(50.5)$ & $355(50.6)$ & $1443(50.5)$ & \multirow[t]{3}{*}{$0.2176^{b}$} \\
\hline Unemployed & $47(7.5)$ & $48(10.2)$ & $47(10.5)$ & $68(11.1)$ & $88(12.5)$ & $298(10.4)$ & \\
\hline Not in labour force & $262(42.1)$ & $182(38.6)$ & $178(39.7)$ & $236(38.4)$ & $259(36.9)$ & $1117(39.1)$ & \\
\hline \multicolumn{8}{|l|}{ Missing = 21} \\
\hline \multicolumn{8}{|c|}{ Paternal / Partner Characteristics ${ }^{d}$} \\
\hline \multicolumn{8}{|l|}{ Paternal age } \\
\hline$<25$ years & $100(16.2)$ & $72(15.4)$ & $81(18.1)$ & $91(14.9)$ & $123(17.6)$ & 467 (16.4) & \multirow[t]{5}{*}{$0.7330^{\mathrm{a}}$} \\
\hline $25-29$ years & $169(27.3)$ & $113(24.2)$ & $123(27.5)$ & $175(28.6)$ & $182(26.0)$ & $762(26.8)$ & \\
\hline 30-34 years & $160(25.9)$ & $144(30.8)$ & $114(25.5)$ & $156(25.5)$ & $186(26.6)$ & $760(26.7)$ & \\
\hline 35-39 years & $120(19.4)$ & $92(19.7)$ & $84(18.8)$ & $121(19.7)$ & $131(18.7)$ & $548(19.3)$ & \\
\hline $40+$ years & $69(11.2)$ & $46(9.9)$ & $45(10.1)$ & $70(11.4)$ & $77(11.0)$ & $307(10.8)$ & \\
\hline \multicolumn{8}{|l|}{ Missing $=35$} \\
\hline \multicolumn{8}{|l|}{ Paternal BMI } \\
\hline Underweight (<18.5) & $127(20.6)$ & $87(18.3)$ & 86 (19.2) & $125(20.5)$ & $129(18.6)$ & $554(19.5)$ & \multirow[t]{4}{*}{$0.3110^{\mathrm{a}}$} \\
\hline Normal weight (18.5-24.9) & $169(27.4)$ & $125(26.4)$ & $127(28.4)$ & $171(28.0)$ & $192(27.6)$ & $784(27.5)$ & \\
\hline Overweight (25.0-29.9) & $229(37.1)$ & $178(37.6)$ & $171(38.3)$ & $206(33.7)$ & $239(34.4)$ & $1023(36.0)$ & \\
\hline Obese $(>30)$ & $92(14.9)$ & $84(17.7)$ & $63(14.1)$ & $109(17.8)$ & $135(19.4)$ & $483(17.0)$ & \\
\hline Missing = 35 & & & & & & & \\
\hline
\end{tabular}


Table 2 Profile of maternal, family and household antenatal exposures for the EFHL cohorts 2006-2010 (Continued)

\begin{tabular}{|c|c|c|c|c|c|c|c|}
\hline Partners highest level & & & & & & & \\
\hline Not complete school & $128(22.0)$ & $88(20.0)$ & $106(24.8)$ & $139(24.3)$ & $148(22.3)$ & $609(22.7)$ & $0.9906^{a}$ \\
\hline Completed high school & $153(26.3)$ & $126(28.6)$ & $96(22.4)$ & $146(25.5)$ & $170(25.6)$ & $691(25.7)$ & \\
\hline Trade/Apprenticeship & $227(39.1)$ & $173(39.3)$ & $174(40.7)$ & $230(40.1)$ & $247(37.3)$ & $1051(39.1)$ & \\
\hline University degree & $73(12.6)$ & $53(12.1)$ & $52(12.1)$ & $58(10.1)$ & $98(14.8)$ & $334(12.4)$ & \\
\hline Missing $=194$ & & & & & & & \\
\hline Partners employment & & & & & & & \\
\hline Employed & $552(93.7)$ & $420(93.7)$ & $395(93.0)$ & $535(91.3)$ & $612(91.2)$ & $2514(92.5)$ & $0.2499^{b}$ \\
\hline Unemployed & $22(3.7)$ & $11(2.5)$ & $15(3.5)$ & $33(5.6)$ & $33(4.9)$ & $114(4.2)$ & \\
\hline Not in labour force & $15(2.6)$ & $17(3.8)$ & $15(3.5)$ & $18(3.1)$ & $26(3.9)$ & $91(3.3)$ & \\
\hline Missing $=160$ & & & & & & & \\
\hline Household Characteris & & & & & & & \\
\hline Annual household inco & & & & & & & \\
\hline Median & $\$ 62,051$ & $\$ 63,295$ & $\$ 62,866$ & $\$ 62,733$ & $\$ 63,786$ & $\$ 62,946$ & $0.4301^{c}$ \\
\hline Lowest quintile & $7.4 \%$ & $6.8 \%$ & $7.0 \%$ & $6.6 \%$ & $7.0 \%$ & $7.0 \%$ & \\
\hline 2nd quintile & $13.2 \%$ & $13.5 \%$ & $12.3 \%$ & $12.9 \%$ & $12.5 \%$ & $12.9 \%$ & \\
\hline 3rd quintile & $17.9 \%$ & $17.6 \%$ & $16.9 \%$ & $17.8 \%$ & $16.5 \%$ & $17.3 \%$ & \\
\hline 4th quintile & $23.1 \%$ & $23.1 \%$ & $22.9 \%$ & $22.8 \%$ & $22.2 \%$ & $22.8 \%$ & \\
\hline Highest quintile & $38.3 \%$ & $39.0 \%$ & $40.9 \%$ & $40.0 \%$ & $41.8 \%$ & $40.0 \%$ & \\
\hline Missing $=449$ & & & & & & & \\
\hline Family status & & & & & & & \\
\hline Sole parent family & $89(14.4)$ & $65(13.7)$ & $57(12.7)$ & $83(13.4)$ & $81(11.6)$ & $375(13.1)$ & $0.6477^{\mathrm{b}}$ \\
\hline Two parent family & $531(85.6)$ & $409(86.3)$ & $393(87.3)$ & $535(86.6)$ & $616(88.4)$ & $2484(86.9)$ & \\
\hline Missing $=20$ & & & & & & & \\
\hline Children in household & & & & & & & \\
\hline No children & $284(46.3)$ & $169(36.7)$ & $163(36.6)$ & $214(34.5)$ & $279(39.5)$ & 1109 (38.9) & $0.0138^{a}$ \\
\hline 1-3 children & $310(50.6)$ & $275(59.7)$ & $265(59.4)$ & $380(61.2)$ & $398(56.4)$ & $1628(57.2)$ & \\
\hline 4 or more children & $19(3.1)$ & $17(3.7)$ & $18(4.0)$ & $27(4.4)$ & $29(4.1)$ & $110(3.9)$ & \\
\hline Missing $=32$ & & & & & & & \\
\hline Changed place of resid & & & & & & & \\
\hline Moved & $282(45.2)$ & $212(44.8)$ & $192(43.4)$ & $257(42.3)$ & $288(41.9)$ & $1231(43.4)$ & $0.7118^{b}$ \\
\hline Did not move & $342(54.8)$ & $261(55.2)$ & $250(56.6)$ & $351(57.7)$ & $399(58.1)$ & $1603(56.6)$ & \\
\hline Missing $=45$ & & & & & & & \\
\hline Satisfaction with area & & & & & & & \\
\hline Satisfied & $542(86.9)$ & $414(87.3)$ & $390(87.3)$ & $526(85.2)$ & 605 (86.6) & 2477 (86.6) & $0.6536^{a}$ \\
\hline Neither & $57(9.1)$ & $41(8.7)$ & $44(9.8)$ & $72(11.7)$ & $72(10.3)$ & $286(10.0)$ & \\
\hline Dissatisfied & $25(4.0)$ & $19(4.0)$ & $13(2.9)$ & $19(3.1)$ & $22(3.1)$ & $98(3.4)$ & \\
\hline Missing $=18$ & & & & & & & \\
\hline $\begin{array}{l}\text { Perceived neighbourhs } \\
\text { connectedness }\end{array}$ & & & & & & & \\
\hline Strong & NA & $59(12.7)$ & 65 (14.6) & $110(18.1)$ & $101(14.7)$ & 335 (15.2) & $0.1297^{a}$ \\
\hline Average & NA & $314(67.8)$ & $299(67.3)$ & $383(63.1)$ & $475(69.0)$ & $1471(66.8)$ & \\
\hline Poor & NA & 90 (19.4) & $80(18.0)$ & $114(18.8)$ & $112(16.3)$ & $396(18.0)$ & \\
\hline
\end{tabular}




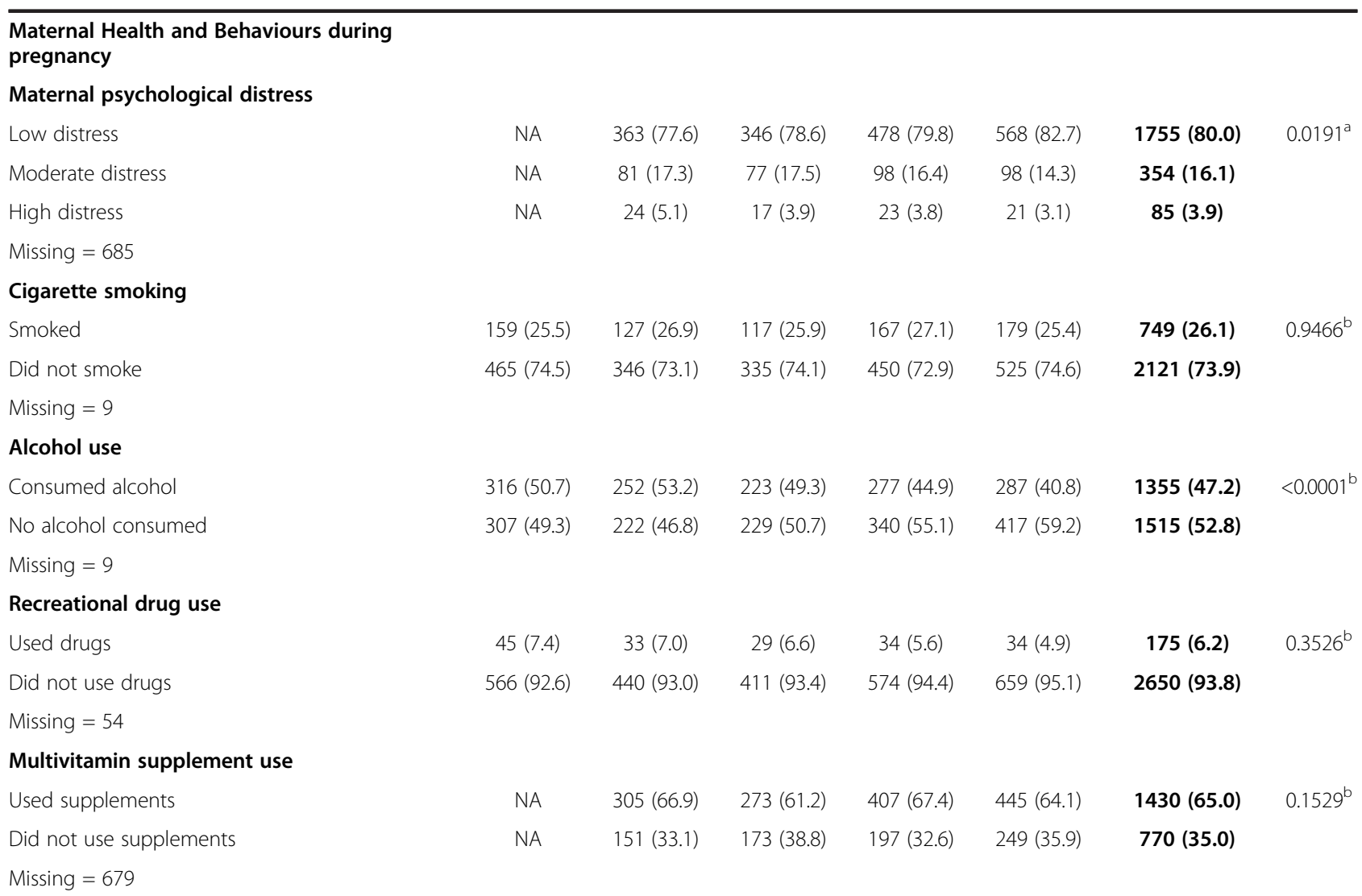

${ }^{a}$ Gamma statistic for ordinal data, ${ }^{\mathrm{b}}$ Pearsons chi-squared test for nominal data, ${ }^{\mathrm{c}}$ Median-test for ordinal data, ${ }^{\mathrm{d}}$ Paternal' indicates biological father, 'Partner' indicates current relationship partner not necessarily the biological father, ${ }^{\mathrm{e}} \mathrm{Gross}$ annual household incomes standardised in AUD\$2010 values.

reported a strong level of neighbourhood and community connectedness, with $43.4 \%$ of families having moved in the 12 months prior to enrolment. Almost two thirds of women reported taking either a multi-vitamin or pregnancy supplement during the pregnancy. Over a quarter of the women reported smoking cigarettes during pregnancy, $47.2 \%$ reported having consumed alcohol, and $6.2 \%$ of women reported some form of recreational drug use during the pregnancy (Table 2). Cannabis was the most common recreational drug used during pregnancy (74.9\%), with ecstasy, methamphetamines/amphetamines and heroin combined accounting for a further $23.4 \%$. Almost $4 \%$ of women scored Kessler 6 high psychological distress levels and $16.1 \%$ moderate distress levels in the four weeks prior to enrolment.

\section{Data stability of antenatal exposures measured for each recruitment cohort}

The five cohorts (2006-2010) were examined for temporal differences in rates of twenty different exposure characteristics across the five years. For the majority of antenatal exposures, there were no significant differences across the years of recruitment, with rates of each factor remaining stable for the five calendar years (Table 2).

Of the four factors where a statistically significant change over time was detected, one showed an anomaly only in the 2006 pilot data. A higher proportion of families had no children living in the household when enrolled in 2006, compared to the four subsequent years of recruitment. When the 2006 pilot data were excluded, this factor remained stable and was no longer statistically significant.

The temporal analysis indicated an increase in the self-reported pre-pregnancy BMI of women being enrolled in the EFHL study between 2006 and 2010. While the proportion of women with a normal pre-pregnancy weight decreased over the five calendar years, the proportion of women with a pre-pregnancy BMI greater than 30 showed some increase, with $18.5 \%$ of the cohort self-reporting pre-pregnancy obesity in 2010 ( $\mathrm{p}=0.0349$ ).

Across the five years, the rates of reported maternal psychological distress changed. Fewer women scored high levels of baseline psychological distress, and conversely there was a significant increase across the calendar 
years in the proportion of women with low psychological distress scores during pregnancy $(\mathrm{p}=0.0191)$.

The factor that demonstrated the most notable variation over the five recruitment years was the self-reported consumption of alcohol during pregnancy. In 2006, 50.7\% of women reported consumption of alcohol and this steadily declined over the five years with a $40.8 \%$ consumption of alcohol during pregnancy reported in 2010 $(\mathrm{p}<0.0001)$.

\section{Discussion}

The results of the analyses of the baseline questionnaire and birth details provide a robust basis for developing a valid and useful epidemiological quantification of the ecological determinants of health. The large study sample is broadly representative of the majority of deliveries in the region, with sufficient range of exposure data to support on-going analyses of research questions relating to the social determinants of health. Temporal and cohort effect analyses indicate strong data stability across five recruitment years.

The three public maternity hospitals from which the study recruited, accounted for $78 \%$ of all births in the study population during 2006-2010. The remaining $22 \%$ of births in the study region occurred either at private hospitals, birthing centres, or were home births and were not represented in the EFHL study sample. The proportion of public hospital deliveries in the study population was higher than the national average of 70\% [27]. Public hospitals are known to serve a disproportionately larger share of patients of relatively low socio-economic status [30]. Women giving birth in public hospitals have been found to be younger, a higher proportion are first births, a greater proportion smoke, and more women present with medical conditions such as hypertension and diabetes [31]. The Health Districts of the study region are known to have higher proportions of socio-economic disadvantage and more people with non-English speaking backgrounds than the national average [9]. These characteristics were similarly reflected in the EFHL sample who demonstrated lower incomes shares, younger age, more overseas born and high proportions of smoking than the national average.

The findings related to the birth sample characteristics suggested that while sampling was broadly representative of the target study population, there were some differences. The EFHL sample included births with greater gestational age, more singletons, higher birth weights, and fewer still births than that of the study population. This study sampled women who were of 24 weeks gestation or later, in waiting rooms attending their routine antenatal clinic visits at public hospitals, during the latter half of the calendar year (except in the 2006 pilot year). Not all antenatal clinics were able to be attended by the research midwifes and short patient waiting times in some clinics prevented the approach of all women, which is likely to have contributed to only half of the estimated births during the recruitment periods being approached for the study. In addition, routine antenatal clinic visits typically include women assessed as low risk births carrying singletons or twins, excluding higher multiple pregnancies or those women with known health conditions associated with an increased risk of birthing complications (mainly premature babies $<28$ weeks gestation). Two studies of South East Queensland births data have shown some seasonal differences in pre-term births, birth weight, and limb length in full-term singleton babies, with heavier babies born in the winter months which coincide with our recruitment periods [32,33].

The repeated sampling design was used in this study to enable the assessment and quantification of the impact of structural or environment changes and health policy implementation during the total recruitment period. The results of the analyses presented here in relation to changing prevalence of alcohol consumption during pregnancy suggest this repeated sampling design is a key strength of the study. Foetal alcohol syndrome and the consumption of alcohol during pregnancy have been the increasing focus of research nationally and internationally, [34-36] resulting in changes to national practice guidelines in 2009, [37] and the development of various state media campaigns in recent years targeting young women, alcohol, and pregnancy [38-40]. Australian studies have found approximately $50 \%-60 \%$ of women drink some alcohol during pregnancy $[34,35,41]$. However, there is a need for temporal examination of prevalence patterns of consumption to have insight into the effectiveness of policy dissemination [42]. The findings of this EFHL study present the first repeated prevalence measure of alcohol consumption during pregnancy in the same geographic population over a five year period. The results demonstrated a 9.9\% reduction in the consumption of alcohol during pregnancy from 2006 to 2010. While beyond the scope of this paper, further analysis will be conducted with regards to changes in risk groups, periods of consumption, frequency, quantity and binge drinking.

The stability of the repeated sample recruitment process can be assessed by comparing the baseline characteristics and antenatal exposure data for each annual cohort. Few of the socio-demographic baseline characteristics of the repeated samples showed significant differences over the five years of data examined. Pre-pregnancy BMI increased over the five calendar years reflecting trend changes found in the national population for the same time period [43]. Caution must be taken with a few individual exposures that demonstrated change over time and a single factor that showed instability in the pilot year when data collection methods were being established 
(number of children living in the household). However, these maternal and socio-demographic factors are not seasonal, and are therefore unlikely to be affected by differences in the months of recruitment. The overall results of this analysis indicate strong robustness of the data and a high degree of stability.

\section{Conclusion}

This paper presents a comprehensive baseline profile of the first five recruitment years of the EFHL birth cohort. Stability of data ascertainment across the recruitment years is strong. The broad representation of socio-economic status, community measures and key proximal exposures such as tobacco, alcohol, and drug intake during pregnancy provides the range of exposure required to ensure identification of effect for relevant risk factors as study outcomes become prevalent. This study, with multiple cohorts from repeated sampling, has the potential to assess health policy implementation during the study period and make important contributions to population health.

\section{Abbreviations}

BMI: Body Mass Index; CPI: Consumer Price Index; EFH: Environments for Healthy Living; FES: Family Environment Scale; K6: Kessler 6;

NCC: Neighbourhood and Community Connectedness; NSW: New South Wales.

\section{Competing interests}

The authors declare that they have no competing interests.

\section{Authors' contributions}

RJM and CMC conceived the idea of EFHL. CMC drafted the manuscript. Al authors contributed to revisions and have read and approved the final manuscript.

\section{Acknowledgements}

The research reported in this publication is part of the Griffith Study of Population Health: Environments for Healthy Living (EFHL) (Australian and New Zealand Clinical Trials Registry: ACTRN12610000931077). Core funding to support EFHL is provided by Griffith University. We are thankful for the crucial contributions of the Project Managers, Rani Scott and the current and past Database Managers. We gratefully acknowledge the administrative staff, research staff, hospital antenatal and birth suite midwives of the participating hospitals for their valuable contributions to the study. Expert advice has been provided by Associate Investigators throughout the project. Dr Cameron was supported by a Public Health Fellowship (ID 428254) from the National Health and Medical Research Council (NHMRC) Australia and Professor Scuffham was supported by a Career Development Award (ID 401742) also from the NHMRC.

\footnotetext{
Author details

${ }^{1}$ School of Medicine, Griffith University, Nathan, QLD 4131, Australia. ${ }^{2}$ Griffith Health Institute, Griffith University, Nathan, QLD 4222, Australia.

${ }^{3}$ Commonwealth Scientific and Industrial Research Organisation (CSIRO) Ecosystem Sciences, Dutton Park, QLD 4102, Australia. ${ }^{4}$ Faculty of Health, Queensland University of Technology, Kelvin Grove, QLD 4059, Australia.

${ }^{5}$ School of Human Services and Social Work, Griffith University, Meadowbrook, Queensland 4131, Australia. ${ }^{6}$ School of Environment, Griffith University, Nathan, QLD 4111, Australia. ${ }^{7}$ Injury Research Institute, Monash University, Melbourne, Victoria 3800, Australia.
}

Received: 23 May 2012 Accepted: 13 December 2012

Published: 15 December 2012

\section{References}

1. Lynch J: Income inequality and health: expanding the debate. Soc Sci Med 2000, 51(7):1001-1005. discussion 1009-1010.

2. Frenk J, Bobadilla JL, Stern C, Frejka T, Lozano R: Elements for a theory of the health transition. Health Transit Rev 1991, 1(1):21-38.

3. Glanz K: Theory at a glance: a guide for health promotion practice. Bethesda, Md: National Institutes of Health, National Cancer Institute; 1995.

4. McLeroy KR, Bibeau D, Steckler A, Glanz K: An ecological perspective on health promotion programs. Heal Educ Q 1988, 15(4):351-377.

5. Diez-Roux AV: Bringing context back into epidemiology: variables and fallacies in multilevel analysis. Am J Public Health 1998, 88(2):216-222.

6. Hanson DW, Finch CF, Allegrante JP, Sleet D: Closing the gap between injury prevention research and community safety promotion practice: revisiting the public health model. Public Health Rep 2012, 127(2):147-155.

7. Keyes KM, Keyes MA, March D, Susser E: Levels of risk: maternal-, middle childhood-, and neighborhood-level predictors of adolescent disinhibitory behaviors from a longitudinal birth cohort in the united states. Ment Health Subst Use 2011, 4(1):22-37.

8. Cameron CM, Scuffham PA, Spinks A, Scott R, Sipe N, Ng S, Wilson A, Searle J, Lyons RA, Kendall E, et al: Environments for healthy living (EFHL) griffith birth cohort study: background and methods. Matern Child Health J 2012 Dec, 16(9):1896-1905.

9. Queensland Health: South Area Health Service Profile. Brisbane: Queensland Government; 2007

10. Furukawa TA, Kessler RC, Slade T, Andrews G: The performance of the K6 and K10 screening scales for psychological distress in the australian national survey of mental health and well-being. Psychol Med 2003, 33(2):357-362.

11. Kessler RC, Barker PR, Colpe LJ, Epstein JF, Gfroerer JC, Hiripi E, Howes MJ, Normand SL, Manderscheid RW, Walters EE, et al: Screening for serious mental illness in the general population. Arch Gen Psychiatry 2003, 60(2):184-189.

12. Moos $\mathrm{RH}$ : Conceptual and empirical approaches to developing familybased assessment procedures - resolving the case of the family environment scale. Fam Process 1990, 29(2):199-208.

13. Moos R, Moos B: In Family environment scale manual: Development, applications, research. 3rd edition. Edited by Alto P. CA: Consulting Psychologist Press; 1994

14. Homel R, Freiberg K, Lamb C, Leech M, Carr A, Hampshire A, Hay I, Elias G, Manning M, Teague $R$, et al: The Pathways to Prevention Project: the first five years. Nathan: Griffith University; 2006:1999-2004.

15. Roberts CL, Lancaster PA: Australian national birthweight percentiles by gestational age. Med J Aust 1999, 170(3):114-118.

16. World Health Organization: Obesity: preventing and managing the global epidemic: report of a WHO consultation. Geneva: World Health Organization; 2000.

17. Australian Bureau of Statistics: Household Income and Income Distribution, Australia, 2009-10; 2011.

18. Australian bureau of Statistics: Comsumer Price Index, Australia 2006-10.

19. Cairney J, Veldhuizen S, Wade TJ, Kurdyak P, Streiner DL: Evaluation of 2 measures of psychological distress as screeners for depression in the general population. Can J Psychiatry 2007, 52(2):111-120.

20. Hilton MF, Scuffham PA, Vecchio N, Whiteford HA: Using the interaction of mental health symptoms and treatment status to estimate lost employee productivity. Aust N Z J Psychiatry 2010, 44(2):151-161.

21. Australian Institute of Health and Welfare: 2004 National Drug Strategy Household Survey: Detailed Findings. Canberra: AlHW; 2005.

22. Queensland Health: Queensland Perinatal Data Collection 2006-2010. Brisbane: Statistical Output, Health Statistics Centre.

23. NSW Ministry of Health: NSW Perinatal Data Collection (HOIST) 2006-2008.

24. Laws PJ, Hilder L: Australia's mothers and babies 2006. Sydney: Australian Institute of Health and Welfare; 2008.

25. Laws PJ, Li Z, Sullivan EA: Australia's mothers and babies 2008. Canberra: Australian Institute of Health and Welfare; 2010.

26. Laws PJ, Sullivan EA: Australia's mothers and babies 2007. Sydney: Australian Institute of Health and Welfare; 2009.

27. Li Z, McNally L, Hilder L, Sullivan EA: Australia's mothers and babies 2009. Sydney: Australian Institute of Health and Welfare; 2011.

28. Australian Bureau of Statistics: Births Australia; 2010.

29. Siegel S, Castellan NJJ: Nonparametric statistics for the behavioral sciences. 2nd edition. New York: McGraw-Hill; 1988 
30. Productivity Commission: Public and Private Hospitals: Research Report. Canberra; 2009.

31. Robson SJ, Laws P, Sullivan EA: Adverse outcomes of labour in public and private hospitals in australia: a population-based descriptive study. Med J Aust 2009, 190(9):474-477.

32. Strand LB, Barnett AG, Tong $\mathrm{S}$ : Maternal exposure to ambient temperature and the risks of preterm birth and stillbirth in brisbane, australia. Am J Epidemiol 2012, 175(2):99-107.

33. McGrath JJ, Keeping D, Saha S, Chant DC, Lieberman DE, O'Callaghan MJ: Seasonal fluctuations in birth weight and neonatal limb length; does prenatal vitamin D influence neonatal size and shape? Early Hum Dev 2005, 81(7):609-618.

34. Colvin L, Payne J, Parsons D, Kurinczuk JJ, Bower C: Alcohol consumption during pregnancy in nonindigenous west australian women. Alcohol Clin Exp Res 2007, 31(2):276-284.

35. O'Callaghan FV, O'Callaghan M, Najman JM, Williams GM, Bor W: Maternal alcohol consumption during pregnancy and physical outcomes up to 5 years of age: a longitudinal study. Early Hum Dev 2003, 71(2):137-148.

36. Ethen MK, Ramadhani TA, Scheuerle AE, Canfield MA, Wyszynski DF, Druschel CM, Romitti PA: Alcohol consumption by women before and during pregnancy. Matern Child Health J 2009, 13(2):274-285.

37. National Health and Medical Research Council (Australia): Australian Guidelines: To Reduce Health Risks from Drinking Alcohol. Canberra: NHMRC; 2009.

38. Centre for Health Promotion: Pregnancy and Alcohol Don't Mix (Social Marketing Campaign). South Australia: Government of South Australia; 2007.

39. Department of Health: No alcohol while pregnant, Strong Spirit Strong Future (Social Marketing Campaign). Western Australia: Parliament of Western Australia; 2011.

40. Queensland Health: Young Women and Alcohol Campaign: Make up your own mind about drinking (Social Marketing Campaign). Queensland: Queensland Government; 2009.

41. Callinan S, Room R: Alcohol consumption during pregnancy: Results from the 2010 National Drug Strategy Household Survey. Melbourne: Centre for Alcohol Policy Research; 2012.

42. O'Leary CM, Heuzenroeder L, Elliott EJ, Bower C: A review of policies on alcohol use during pregnancy in australia and other english-speaking countries, 2006. Med J Aust 2007, 186(9):466-471.

43. Australian Institute of Health and Welfare: Australia's health 2010. Canberra: AlHW; 2010.

doi:10.1186/1471-2458-12-1080

Cite this article as: Cameron et al: Environments For Healthy Living (EFHL) Griffith birth cohort study: characteristics of sample and profile of antenatal exposures. BMC Public Health 2012 12:1080.

\section{Submit your next manuscript to BioMed Central and take full advantage of:}

- Convenient online submission

- Thorough peer review

- No space constraints or color figure charges

- Immediate publication on acceptance

- Inclusion in PubMed, CAS, Scopus and Google Scholar

- Research which is freely available for redistribution 